LA-UR- $\quad 98-1163$

Title:

Author(s):

Submitted to:
DEVELOPMENT OF ENERGY-DISPERSIVE X-RAY FLUROESCENCE AS A MOBILE ANALYSIS METHOD FOR HAZARDOUS METALS IN TRANSURANIC WASTE

$$
\text { CONF-980581-- }
$$

S. J. Goldstein
Enviroanalysis 198 Conf., Ottawa, Ontario Canada $5 / 11-14 / 98$

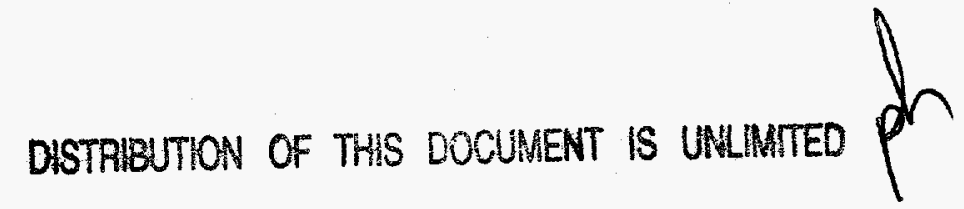

MASTER

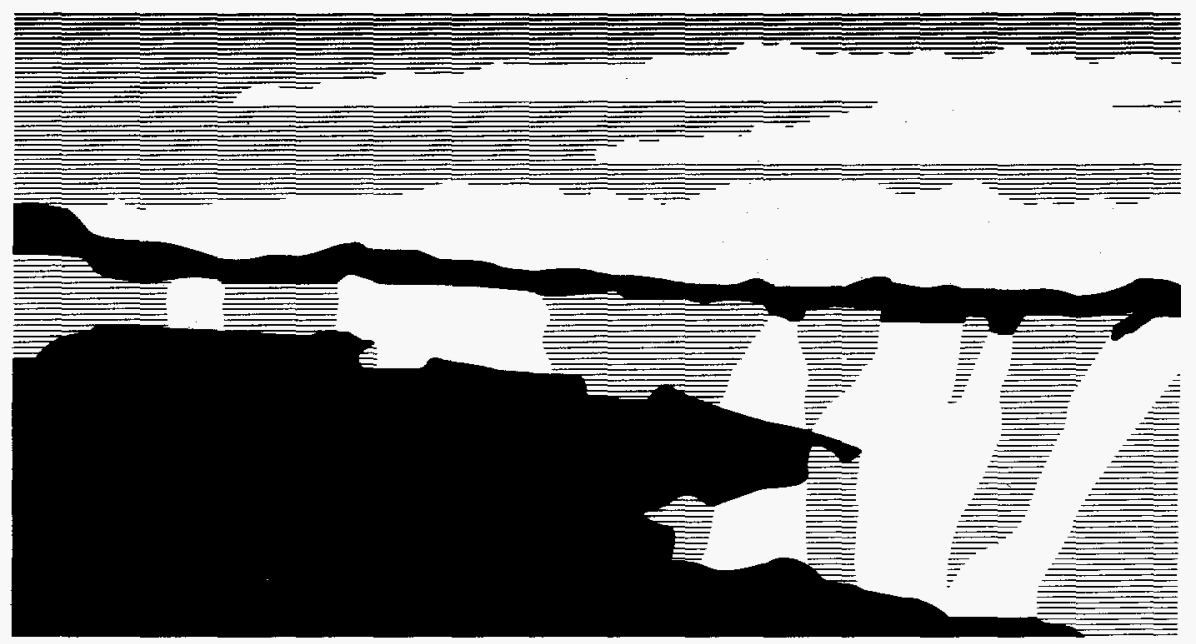

Los Alamos National Laboratory, an affirmative action/equal opportunity employer, is operated by the University of California for the U.S. Department of Energy under contract W-7405-ENG-36. By acceptance of this article, the publisher recognizes that the U.S. Government retains a nonexclusive, royalty-free license to publish or reproduce the published form of this contribution, or to allow others to do so, for U.S. Government purposes. The Los Alamos National Laboratory requests that the publisher identify this article as work pertormed under the auspices of the U.S. Department of Energy. 


\section{DISCLAIMER}

This report was prepared as an account of work sponsored by an agency of the United States Government. Neither the United States Government nor any agency thereof, nor any of their employees, makes any warranty, express or implied, or assumes any legal liability or responsibility for the accuracy, completeness, or usefulness of any information, apparatus, product, or process disclosed, or represents that its use would not infringe privately owned rights. Reference herein to any specific commercial product, process, or service by trade name, trademark, manufacturer, or otherwise does not necessarily constitute or imply its endorsement, recommendation, or favoring by the United States Government or any agency thereof. The views and opinions of authors expressed herein do not necessarily state or reflect those of the United States Government or any agency thereof. 


\section{DISCLAIMER}

Portions of this document may be illegible in electronic image products. Images are produced from the best available original document. 


\title{
Development of Energy-Dispersive X-Ray Fluorescence as a Mobile Analysis Method for Hazardous Metals in Transuranic Waste
}

Steven J. Goldstein, Los Alamos National Laboratory, Inorganic Trace Analysis, Group CST-9, MS K484, Los Alamos, NM 87545.

\begin{abstract}
Energy-dispersive $\mathrm{X}$-ray fluorescence (EDXRF) is a widely applied technique for both laboratory and field-based characterization of metals in complex matrices. Here an EDXRF method is described for analysis of 13 hazardous (RCRA) metals in Portland cement, a typical matrix for transuranic (TRU) waste from U.S. Department of Energy (DOE) sites. Samples are analyzed as homogeneous powders prepared by simple drying, mixing, and milling. Analyses are performed using a commercial EDXRF spectrometer equipped with an $\mathrm{X}$-ray tube, a high-resolution $\mathrm{Si}(\mathrm{Li})$ detector, and fundamental parameters software for data reduction. The spectrometer is rugged and suitable for use in either mobile or fixed-base laboratories. Standardization is accomplished using fundamental parameters techniques for several prepared standards which bracket the expected range in metal concentrations, and typical standardization uncertainties are $<10 \%$. Detection limits range from 2,-20 ppm and meet required action levels with a few exceptions including $\mathrm{Be}, \mathrm{Hg}$ and $\mathrm{V}$. Accuracy is evaluated from a series of unknown quality control samples and ranges from $85-102 \%$, whereas the total method uncertainty is typically $<10 \%$. Consequently, this simple, rapid, and inexpensive technique can provide quantitative characterization of virtually all of the RCRA metals in TRU waste cement samples.
\end{abstract}

Background and Objectives: Analysis of RCRA (i.e. Resource Conservation and Recovery Act) metals is an imminent and critical compliance activity required prior to transuranic (TRU) waste treatment and/or disposal. Transuranic waste is solid radioactive waste that contains alpha-emitting radionuclides of atomic number greater than uranium with half-lives greater than 20 years in concentrations greater than $100 \mathrm{nCi} / \mathrm{g}$. The U.S. DOE plans to dispose of approximately 175,600 cubic meters of TRU waste at the Waste Isolation Pilot Plant (WIPP) site near Carlsbad, NM, all of which will have to be characterized for RCRA-regulated metals prior to disposal.

Current methods of waste characterization and analysis (i.e. ICPMS, ICPAES, CVAA) for RCRA-regulated metals are laboratory-based, costly, have low sample throughput, and are not readily amenable for mobile deployment. Field-based techniques are desired due to the difficulty and cost of transporting TRU waste from generating sites to analytical laboratories for the purposes of characterization. Hence, various mobile analytical capabilities for direct solid analysis of metals are being investigated in the hope of substantially reducing costs ( by $\sim 100 \mathrm{M} \$$ across the entire DOE complex ) and improving performance. 
EDXRF is one of several methods of direct solid analysis which can potentially provide improvements in analytical performance (i.e. cost, turnaround time, field-based characterization) over traditional wet chemical methods of analysis. Recent developments in field-transportable EDXRF have greatly improved the sensitivity and accuracy of this method for elemental analysis of complex matrices (e.g. Pella et al., 1986; Leyden, 1988; Bilbrey et al., 1988; de Boer, et al., 1993). Our recent work with EDXRF for soil characterization indicated that it was relatively accurate and sensitive for most $R C R A$ metals, with typical biases of $<+/$ $10 \%$ and detection limits as low as a few ppm (Goldstein et al., 1996). Hence, a major objective was to develop and evaluate an analogous EDXRF method for analysis of Portland cement waste samples over a range of elements and concentrations suitable for RCRA metal analysis.

Method: The methodology for sample preparation and analysis in EDXRF is relatively straightforward, largely following methods previously developed for soil analysis (Watson et al., 1989; Goldstein et al., 1996). Samples are dried under a heat lamp overnight, mixed and milled in a Spex ball-mill for 5 minutes, sieved to $<100$ um size, and then $\sim 0.5 \mathrm{~g}$ placed as a powder in a microcell for analysis. This simple method of sample preparation takes $<20$ minutes per sample, but provides a physically homogeneous sample needed for reproducible $\mathrm{XRF}$ analysis. It is also simple and fast enough to be amenable to be completed in a mobile analytical laboratory. Sample size is reduced by a factor of $10-20$ relative to conventional powder XRF through use of a sample microcell and beam collimator.

All analyses were performed using a commercial EDXRF spectrometer, a Spectrace 5000. This instrument has an X-ray tube source with variable source current and voltage up to $1 \mathrm{~mA}$ and $50 \mathrm{kV}$, which permits optimization of excitation conditions for the element of interest. It also uses a high-resolution, electrically cooled $\mathrm{Si}(\mathrm{Li})$ detector which permits simultaneous collection of $\mathrm{x}$-rays of variable energy with minimal spectral interference. The instrument has a fundamental parameters data reduction package available for rapid multi-element standardization and quantitation of the acquired spectra. A nearly identical field-transportable instrument is also available, and so performance of this method should be similar under field conditions.

Analytical conditions were optimized to increase method sensitivity by adjusting the excitation $x$-ray tube voltage and current. Filters of various thickness and composition were also used to remove low energy noise from the acquired spectra. Based on tests with standards, four separate excitation conditions were used: 1) lowest- $\mathrm{Z}$ elements $\mathrm{Ca}, \mathrm{V}, \mathrm{Cr}$ using $12 \mathrm{kV}$ tube voltage, $0.13 \mathrm{~mm}$ thick $\mathrm{Al}$ filter, 2) $\mathrm{Fe}, \mathrm{Ni}, \mathrm{Cu}$, and $\mathrm{Zn}$ using $20 \mathrm{kV}$ tube voltage, $0.05 \mathrm{~mm}$ thick $\mathrm{Pd}$ filter, 3) As, $\mathrm{Se}, \mathrm{Hg}, \mathrm{Tl}, \mathrm{Pb}, \mathrm{U}$, and Th using $35 \mathrm{kV}$ tube voltage, $0.127 \mathrm{~mm}$ thick $\mathrm{Pd}$ filter, and 4) $\mathrm{Ag}, \mathrm{Cd}, \mathrm{Sb}$, and $\mathrm{Ba}$ using $50 \mathrm{kV}$ tube voltage, $0.63 \mathrm{~mm}$ thick $\mathrm{Cu}$ filter. Acquisition time (livetime) was $800 \mathrm{~s}$ per condition, hence analysis takes approximately 90 minutes per sample. This long acquisition time was needed to achieve detection limits at the desired levels utilizing the relatively small sample configuration of the microcell geometry. Samples were analyzed utilizing an auto-sampling turret in automated mode overnight, so throughput is presently $\sim 10$ 15 samples/day. Spectral interferences are generally absent under the conditions above. 
Standardization of the major elements was accomplished by cement standards spanning a range in composition obtained from NIST. A dual approach was used to standardize the trace metals. Trace element standards containing the metals of interest were obtained from prior TRU intercomparison studies. Because these standards spanned a limited range in concentration, additional standards were prepared at LANL by adding NIST-traceable multielement solution standards onto a "blank" cement matrix, followed by drying and homogenization. A total of 6 multi-element standards typically ranging from $10-2000 \mathrm{ppm}$ were used for standardization.

Results: Detection limits for the conditions above are compared to the TRU waste program required detection limits in Table 1. The EDXRF technique meets detection limit requirements for 11 of the 14 metals. Exceptions are $\mathrm{V}, \mathrm{Hg}$, and $\mathrm{Be}$, the latter of which is not detected by EDXRF. The detection limit for vanadium is only a factor of two above the required limit, and so it is likely that the required limit could be met by increasing data acquisition time by a factor of 4 or by increasing sample size. However, the required detection limit for mercury is a factor of 40 too low and apparently unattainable by direct EDXRF techniques. Additional fieldbased techniques which can more sensitively measure both mercury and beryllium are required for waste characterization of RCRA metals.

Table 1. EDXRF and Program Required Detection Limits (3 $\sigma$ )

\begin{tabular}{|l|r|l|}
\hline Element & $\begin{array}{l}\text { EDXRF } \\
\text { Detection Limit } \\
(\mathbf{p p m})\end{array}$ & $\begin{array}{l}\text { Program Required } \\
\text { Detection Limit } \\
(\mathbf{p p m})\end{array}$ \\
\hline Antimony & 3 & 10 \\
\hline Arsenic & 4 & 10 \\
\hline Barium & 10 & 200 \\
\hline Beryllium & -- & 10 \\
\hline Cadmium & 2 & 2 \\
\hline Chromium & 8 & 10 \\
\hline Lead & 5 & 10 \\
\hline Mercury & 9 & 0.4 \\
\hline Nickel & 5 & 10 \\
\hline Selenium & 2 & 2 \\
\hline Silver & 2 & 10 \\
\hline Thallium & 6 & 10 \\
\hline Vanadium & 20 & 10 \\
\hline Zinc & 2 & 10 \\
\hline & & \\
\hline
\end{tabular}

Relative standardization uncertainties (\%RSD), based on agreement of the six trace-element standards, are given in Table 2. The uncertainty due to standardization is $10 \%$ or less for 10 of the 13 detected metals. Exceptions are $\mathrm{Hg}, \mathrm{Ag}$, and $\mathrm{Ba}$, which have significantly poorer precision. The higher standardization uncertainties for barium and silver seem to reflect some small bias in the certified values for either the LANL or externally prepared trace element 
standards for these elements. The high uncertainty for mercury reflects its low concentration, ranging from 7 to $54 \mathrm{ppm}$ in the standards measured.

External precision and accuracy are evaluated from results for three blind quality control samples, given in Table 2. The typical external precision is based on reproducibility of analyses of three replicate aliquots of three different QC samples. For all elements with the exception of $\mathrm{Hg}$, this relative uncertainty is less than $7 \%$. Again, mercury has poorer reproducibility due its lower concentration in the analyzed samples. Based on these results for samples above the quantitation level, a typical external precision of a few percent can be obtained with this EDXRF method.

Table 2 also shows that average accuracy ranges from $85 \%$ for $\mathrm{Cr}$ to $102 \%$ for $\mathrm{Ni}$. Results for vanadium are relatively poor due to its high detection limit and are not included. Given the total propagated uncertainties based on standardization and external precision in Table 2, none of the other elements show a significant bias at the $95 \%$ confidence interval.

Table 2. EDXRF Method Precision and Accuracy

\begin{tabular}{|l|r|l|r|l|r|}
\hline Element & $\begin{array}{l}\text { Concentration } \\
\text { Range (ppm) }\end{array}$ & $\begin{array}{l}\text { Standardization } \\
\text { Uncertainty }^{\mathbf{a}} \\
\text { (\% RSD) }\end{array}$ & $\begin{array}{l}\text { External } \\
\text { Precision } \\
\text { (\% RSD) }\end{array}$ & $\begin{array}{l}\text { Total } \\
\text { Propagated } \\
\text { Uncertainty } \\
\text { (\% RSD) }\end{array}$ & $\begin{array}{l}\text { Average } \\
\text { Accuracy } \\
(\%)\end{array}$ \\
\hline Antimony & $98-263$ & 8 & 6 & 10 & 91 \\
\hline Arsenic & $173-490$ & 5 & 3 & 6 & 98 \\
\hline Barium & $1660-5770$ & 20 & 6 & 21 & 94 \\
\hline Cadmium & $89-107$ & 8 & 5 & 9 & 89 \\
\hline Chromium & $202-561$ & 7 & 3 & 8 & 85 \\
\hline Lead & $192-277$ & 4 & 5 & 6 & 96 \\
\hline Mercury & $16-23$ & 46 & 19 & 50 & 87 \\
\hline Nickel & $104-581$ & 5 & 4 & 6 & 102 \\
\hline Selenium & $28-98$ & 7 & 5 & 9 & 97 \\
\hline Silver & $198-229$ & 17 & 6 & 18 & 96 \\
\hline Thallium & $242-547$ & 7 & 5 & 9 & 91 \\
\hline Vanadium & $81-433$ & 10 & 7 & 12 & --- \\
\hline Zinc & $238-385$ & 6 & 3 & 7 & 96 \\
\hline
\end{tabular}

" Concentration range for quality control samples used to determine external precision and accuracy.

Standardization uncertainty based on six known standards typically ranging from 10-2000 ppm.

Conclusions: These results indicate that field-based EDXRF techniques can meet requirements for analyses of a large majority of the RCRA-metals in TRU waste samples. While EDXRF appears to be suitable for analyses of 11 of the 14 RCRA-metals, a few metals 
including mercury, vanadium, and beryllium have detection limits which are significantly above the program requirements. As a result, additional techniques should be investigated for characterization of those metals. In addition, effects of inherent radiation of the samples and matrix variability on method performance need to be investigated, although these effects are expected to be relatively minor in most cases.

\section{References:}

Bilbrey, D. B.; Bogart, G. R.; Leyden, D. E.; Harding, A. R. X-Ray Spectrom. 1988, 17, 63. de Boer, D. K. G.; Borstrok, J. J. M.; Leenaers, A. J. G.; van Sprang, H. A. X-Ray Spectrom. 1993, 22, 33.

Goldstein, S. J.; Slemmons, A. K.; Canavan, H. E. Env. Sci. Technol. 1996, 30, 2318. Leyden, D. E. Spectroscopy 1988, 2, 28.

Pella, P. A.; Tao, G. Y.; Lachance, G. X-Ray Spectrom. 1986, 15, 251.

Watson, W.; Walsh, J. P.; Glynn, B. American Laboratory 1989, $21,60$. 